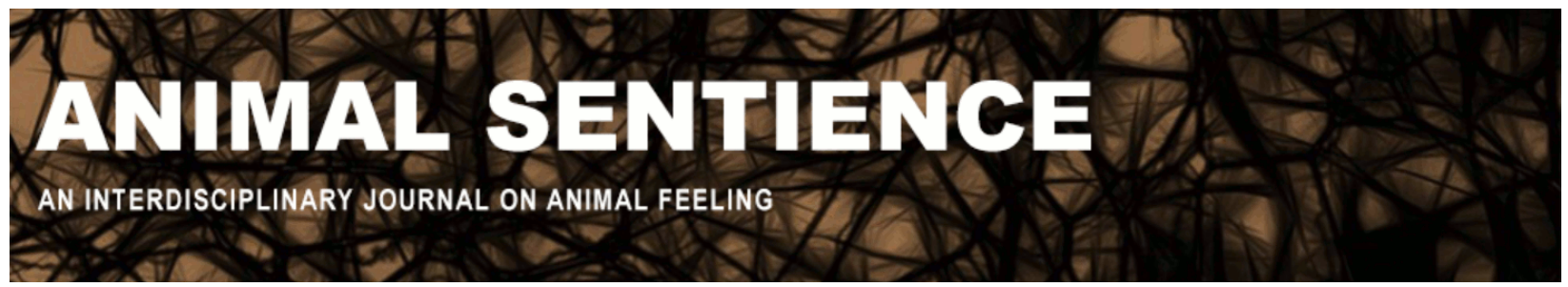

Barone, Pamela and Gomila, Antoni (2016) In what sense are you a person?. Animal Sentience 10(16)

DOI: $10.51291 / 2377-7478.1169$

Date of submission: 2016-10-01

Date of acceptance: 2016-10-18

(c)

This article has appeared in the journal Animal

Sentience, a peer-reviewed journal on animal

cognition and feeling. It has been made open access,

free for all, by WellBeing International and deposited

in the WBI Studies Repository. For more information,

please contact

wbisr-info@wellbeingintl.org.

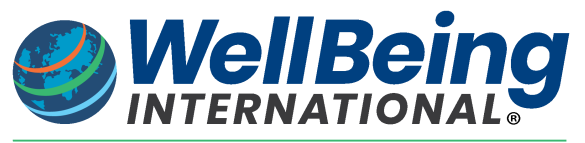

SOLUTIONS FOR PEOPLE, ANIMALS AND ENVIRONMENT 


\title{
In what sense are you a person?
}

Commentary on Rowlands on Animal Personhood

\author{
Pamela Barone \& Antoni Gomila \\ Department of Psychology \\ University of the Balearic Islands
}

\begin{abstract}
According to Rowlands, personhood in nonhuman animals calls for a unified mental life and pre-reflective self-awareness provides this. The concept of "person" is fuzzy. Any attempt to define it with necessary and sufficient conditions faces the problem of borderline cases satisfying only some of the conditions to varying degrees. We ask about the implications of a metaphysical sense of personhood for its moral and legal sense. Finally, we address Rowlands's reliance on pre-reflective self-awareness and present our own criteria for personhood.
\end{abstract}

Keywords: personhood, moral agency, nonhuman animals, self-awareness, intersubjectivity

Pamela Barone, PhD candidate in the Human
Cognition and Evolution Programme (University of
the Balearic Islands), does research on
understanding others' minds from a
developmental and comparative perspective.
http://evocog.org/en/people/

Antoni Gomila, Professor of Psychology (University of the Balearic Islands), is interested in what makes us human, from an evolutionary perspective. https://antonigomila.wordpress.com/
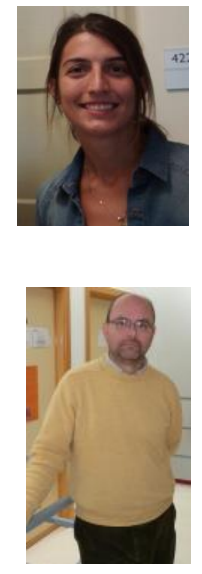

Rowlands (2016a) proposes that having a unified mental life is the defining criterion for being a person. According to this notion, a person is a self-aware entity. Rowlands is thereby modifying Locke's (1690) view of a person as the entity that has the ability to "consider itself as the same thinking thing, in different times and places" (p. 280) in two ways. Rowlands rejects that self-awareness has to be reflective and that mental unity has to endure in time. For him, the sort of unity of mental life Locke advocated is already found in entities capable of having experiences: to have an experience is to experience something "as something." This only requires having implicit expectations and anticipations regarding what is to happen to the self, so having experiences amounts to pre-reflective awareness of oneself. Having experiences involves the sort of mental unification sufficient for personhood (Rowlands, 2016b). Therefore, insofar as nonhuman animals have experiences, they are persons.

This position contrasts with what Rowlands argued in previous work. Rowlands (2012) contended that, to be a person, an entity must exhibit some degree of moral sensitivity, such as showing emotions with an identifiable moral content. As long as some animals' acts are motivated by moral emotions like compassion or resentment, they can be considered moral subjects. Given this view of personhood, some social mammals qualify.

Rowlands (2016a) offers an even broader view of personhood, but it is doubtful that his new strategy succeeds. On the one hand, the concept of "person" is fuzzy: any attempt to 
define it by means of necessary and sufficient conditions has to deal with the problem of borderline cases satisfying only some of the conditions to varying degrees. On the other hand, his proposal disconnects the metaphysical concept of person from its moral and legal aspects. There is also an essential problem with Rowlands's reliance on pre-reflective self-awareness to define personhood. In what follows we will discuss these three difficulties.

First, the conditions for personhood must be indisputably satisfied for paradigmatic instances. Only later will it be possible to assess to what extent non-paradigmatic cases fulfill these requirements and whether they should be included in the class of persons, even if as "limit cases" (Gomila, 1997). Rowlands's criterion, though, turns all sorts of limit cases into central ones as long as "having experiences" is all that matters for personhood. This is to overlook multiple features that have played a more central role in our understanding of personhood, such as a sense of self or agential structure. In addition, new forms of borderline cases arise, such as whether an entity is really having experiences.

Second, Rowlands's liberal view of persons would lose any normative (legal or moral) strength that our common notion of person may have regarding those central features. While he outlines a sharp distinction among metaphysical, moral and legal notions of personhood, these need to be related. Rowlands appears to conceive the metaphysical person as a necessary but not sufficient condition for being a moral person because he recognizes that the metaphysical conception has moral implications (Rowlands, 2016b). However, it is not clear from his proposal what else, beyond being a metaphysical person, would be needed to be a moral and legal person. Whatever the answer, the further question arises as to why not include this in the metaphysical notion. Referring only to the metaphysical definition, neglecting animals' moral and juridical status, is also questionable because common conceptions in different disciplines might help to cast new light onto unresolved issues or borderline cases.

Paradoxically, being a legal person does not require being human, alive or self-conscious. The legal notion of personhood also includes legally generated juridical persons such as firms, partnerships, associations, corporations, etc. (Garner, 2009) but not animals, showing again the fuzziness of the concept, and the centrality of agency. Rowlands's liberal notion would require a vast legal reform posing serious practical problems. Fortunately, we need not personify all the beings in the environment in order to legally protect animals (Picasso, 2015).

Finally, Rowlands's notion of pre-reflective self-awareness is problematic. Lacking operational criteria to establish whether an animal is capable of pre-reflective self-awareness, his proposal may be unable to distinguish between "experiencing as" and mere low level, nonintentional expectations and anticipations. A dog may react to the sight of its owner catching the leash and prepare to go out, but this event can be described without appealing to any form a self-awareness. This is similar to babies anticipating and adjusting to their mothers' approach (Reddy, Markova, \& Wallot, 2013). Rowlands's only suggestion for connecting pre-reflective to reflective self-awareness would entail that dogs and babies are not pre-reflectively selfaware given that there is no appropriate context in which they can activate the "requisite meta-cognitive abilities" they lack.

Worse still, pre-reflective self-awareness falls short of the kind of psychological continuity that a Lockean account of personhood requires. It lacks the continuity across time and place that Locke argued for. As Kant's classical objection goes: this sequence of unities is not the same "as an experience of continuity." A person requires the kind of temporal continuity that Rowlands's proposal is unable to provide. 
In our view, the basic criterion for personhood is being able to engage in intersubjective interactions. That's why the concept of person also involves a normative dimension. To recognize individuals as persons is to recognize that they have moral status and belong to a network of rights and duties: "others are understood as persons because we are capable of engaging with them in specific patterns of intersubjective interaction that include emotional and expressive behaviors" (Gómez, 1998, p. 56). As a result, a special kind of mutualawareness is crucial for personhood. In development, other-awareness is inseparable from self-awareness: the self is a dialogic entity, existing only in relation and therefore knowable only as a relation (Reddy, 2008). From this point of view, apes qualify as persons (Gómez, 1998; Gomila, 1997; Barone \& Gomila, 2015). ${ }^{1}$

In taking this approach we advocate the same respectful and caring attitudes toward nonhuman persons as those we have toward humans in equivalent borderline situations, such as infants (Gomila, 1997). Actually, "the sort of treatment we owe an animal is not independent of the sort of thing it is and the features it has" (Rowlands, 2016b, p. 3). But we do not need a wide, liberal notion of personhood to guarantee this treatment. Only some nonhuman animal species count as persons.

\section{References}

Barone, P., \& Gomila, A. (2015, July). The case for non-human primates as persons. Poster presented at the $23^{\text {rd }}$ Annual European Society of Philosophy and Psychology Conference, Tartu, Estonia.

Garner, B. A. (2009). Black's Law Dictionary (9th ed.). St. Paul, Minn.: West Publishing Company.

Gómez, J. C. (1998). Are apes persons? The case for primate intersubjectivity. Etica \& Animali, 9, 51-63.

Gomila, A. (1997). Personas primates. In J. M. García Gómez-Heras (Ed.), Ética del medio ambiente. Madrid: Tecnos.

Locke, J. (1690). An Essay Concerning Human Understanding. London: J. M. Dent and Sons, 1961.

Picasso, S. (2015, April 16). Reflexiones a propósito del supuesto carácter de sujeto de derecho de los animales. Cuando la mona se viste de seda. La Ley, pp. 1-10. Buenos Aires. Retrieved from http://thomsonreuterslatam.com/2015/04/29/reflexiones-aproposito-del-supuesto-caracter-de-sujeto-de-derecho-de-los-animales-cuando-la-monase-viste-de-seda-autor-picasso-sebastian/

Reddy, V. (2008). How infants know minds. Harvard: Harvard University Press.

Reddy, V., Markova, G., \& Wallot, S. (2013). Anticipatory adjustments to being picked up in infancy. PloS One, 8(6).

Rowlands, M. (2012). ¿Pueden los animales ser morales? Dilemata, 9, 1-32.

Rowlands, M. (2016a). Are animals persons? Animal Sentience 2016.101.

Rowlands, M. (2016b). Consciousness and the unity of mind. Animal Sentience 2016.144.

\footnotetext{
${ }^{1}$ Consequently, the latest writs of habeas corpus in favor of apes' freedom, and against their arbitrary arrests, would be perfectly legitimate. Other species of animals should also be analyzed under this criterion to determine whether they qualify as well.
} 